\title{
36
}

\section{WETLANDS AS POLLUTION PROCESSORS}

\author{
Jan Herrmann \\ Ann-Karin Thorén \\ University of Kalmar, Sweden
}

\begin{abstract}
After decades of successful measures against point sources of nutrients in industrial countries, we still have severe problems with diffuse pollution. For treatment of excessive nitrogen from agricultural and urban areas, in the form of nitrate $\left(\mathrm{NO}_{3}{ }^{-}\right)$and ammonium $\left(\mathrm{NH}_{4}{ }^{+}\right)$, wetlands (including dams and buffer zones) are constructed to favour the microbial processes that lead to denitrification of $\mathrm{NH}_{4}^{+}$and $\mathrm{NO}_{3}{ }^{-}$, via nitrite $\left(\mathrm{NO}_{2}{ }^{-}\right)$and nitrous oxide $\left(\mathrm{N}_{2} \mathrm{O}\right)$, to atmospheric nitrogen $\left(\mathrm{N}_{2}\right)$. Important factors when designing "optimal wetlands" are hydrology, temperature, sufficient carbon source, water residence time, and alternating aerobic/anaerobic conditions. Also biomass uptake and sedimentation of both nitrogen and phosphorus help with reduction of the nutrients. Conditions and possibilities for wetlands in their accumulation of storm water are also described. The importance of biological diversity in wetlands are several: more fragmentation by invertebrates, more plant surface types, more nutrient biomass uptake, more bioturbation by various animals, and more biomass that can accumulate toxicants. The efficiency and biodiversity of wetlands are due to their trait being ecotones between land and water, causing large spatial and temporal variations. Finally the recreational, esthetical and broad pedagogical values of wetlands, as well as the need of better follow-up studies, are emphasised.

Keywords: Wetland, freshwater, nutrient, nitrogen, denitrification, phosphorus, metals, ecotone, buffer zone, biodiversity.
\end{abstract}

\section{INTRODUCTION}

Running waters and along these, lakes, dams, wetlands and buffer zones, have always been instrumental for getting rid of pollutants, using the high self-purification capacity, but also "for sending the stuff elsewhere". However, negative effects on fresh and marine water quality and life accelerated throughout the last century. In the rich and developed countries, our relatively good knowledge and technology for treatment of standard point-source pollution have lowered the effluents, but also due to better farming practices. Remaining diffuse pollution of different kinds, combined with the insight of nitrogen as the main primary production regulator in marine areas, have during the last one or two decades directed much interest towards the possibilities to reconstruct wetlands of various kinds along the watercourses. Nitrogen is the main pollutant to be reduced in such arrangements (Swedish EPA 1997). Also storm water, containing metals and other contaminants, is more frequently 
directed towards wetlands. Moreover, arranged waterbodies seem to favour biological diversity (Gee et al. 1997).

Ever since the Great Ice Age, Sweden has been very rich in lakes and wetlands. During the last century or more, in many regions a majority of these were lowered or totally drained, and at the same time many of the watercourses were straightened to ditches, with the need to dredge them regularly (Leonardson 1994). During earlier decades, reasons for these drastic changes in the landscape and ecosystem functions were the needs of more arable land for the growing human population, and the fact that Sweden was then a poor country. In later decades, increased ditching of wetlands has also taken place in the vast forested areas, in connections with plantations and logging activities.

With the decreasing water occurrence, many favourable traits and effects of wetlands (in a broad sense, see below) were lost, being fundamental for their advantageous mechanisms (Fig. 1). The most important ones are 1) counteracting rapid changes in water flow; 2) allowing biomass growth to more effectively incorporate excess nutrients as phosphorus and nitrogen, but also other (unwanted) compounds; 3) increasing the water retention time, thereby promoting the bacterial activity to reduce nitrate to atmospheric nitrogen; 4) giving more complex habitats, yielding a large variety of plants, invertebrates, fish and birds, thus an increased biodiversity, of both utility and pleasure.

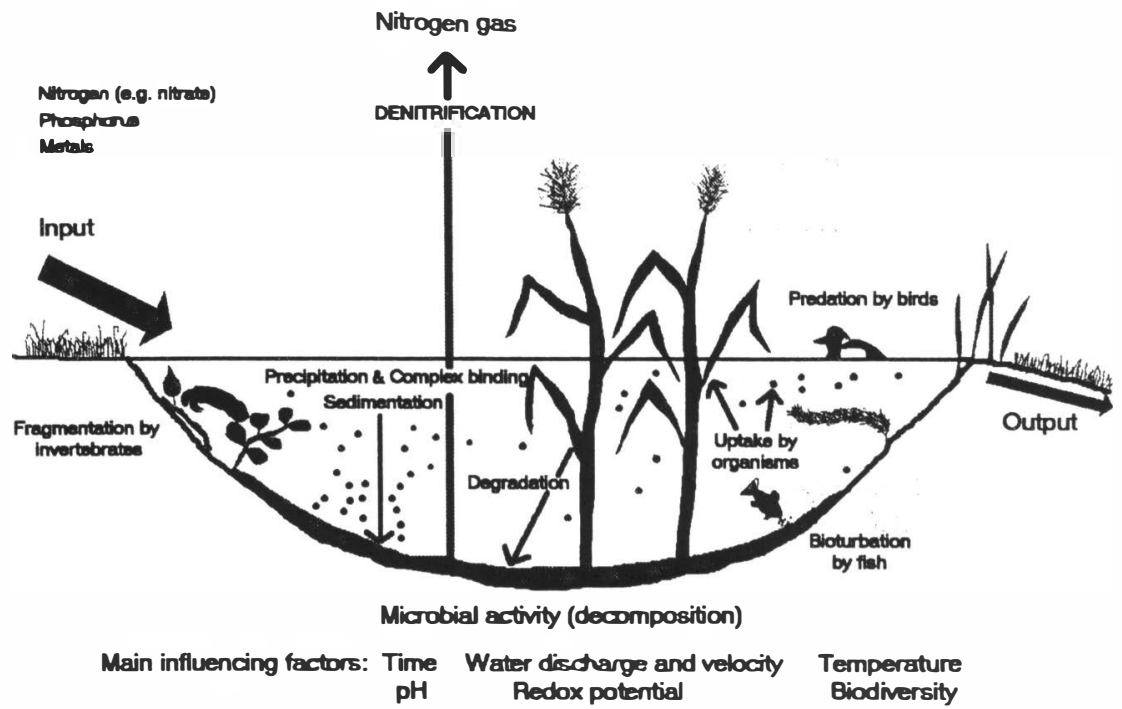

Fig. 1. Processes and processors in a typical wetland, primarily designed for reduction of nitrogen, and/or accumulation of metals. Main influencing factors are shown below the wetland. 


\section{WHAT IS A WETLAND?}

Several definitions of the concept "wetland" exist, being confusing and sometimes contradictory. Quite often is used the Ramsar Convention on Wetlands (Finlayson and Moser 1991):

Areas of bogs, marshes or water, natural or artificial, permanent or temporary, with stagnant or flowing water, being fresh, brackish or salt, including marine areas, where the depth at low-water does not exceed 6 meter.

It seems important that this definition also can include water saturated areas, but with no superficial water. Further it can also include littoral parts of all standing waters, as well as low order streams. A unifying concept for all these habitats is the ecological word "ecotone", implying that the areas are transitory habitats between land and water. Since long time, it has been supposed or shown (Lachavanne and Juge 1997) that such ecotones can be characterised by 1) high rates in biogeochemical cycles, giving efficient both primary and secondary productions; 2) rapid decomposition and transformation rates; 3) high biodiversity numbers, due to spatial and temporal complexity in water occurrence; and finally, that 4) such areas are highly important for spawning, feeding and growing of a large variety of fish, birds and invertebrates, also from areas adjacent to these ecotones, thus the deeper water parts and land (Herrmann 1999).

The broadened definition of wetland (see above) is used onwards. From plant ecological points, a more complex subdivision of wetlands can be made, as presented by Thorén (1999a). Wetlands are dominated by hydrophytes, i.e. all those plants that are adapted to live seasonally or permanently in flooded soils/sediments, often at anaerobic conditions. Quite often wetlands are additionally defined by that at least $30 \%$ of the vegetation is dominated by hydrophytes, at least periodically (Mitsch and Gosselink 1993).

Buffer zones are strips alongside running waters in agricultural or forested areas, but not necessarily met by the definitions of wetlands given above. Buffer zones are often only 5-10 meters broad (on each side), only extensively cultivated, and often regarded as important for catching nutrients and pesticides, but also offering habitats for a substantially increased biodiversity. The latter advantage is especially important in agricultural areas dominated by large monocultures of crops or forestry. Such a fringe of "more natural" vegetation is supposed to give a much more diverse habitat in the buffer zone itself, as well as the water, thus good for plants, invertebrates and fish. This hopefully results in more natural functions in the water than if the fields were all the way to the water (see below). The water run-off is today often led into a ditch, which however would be favoured by being transformed into a more meandering system, and/or with a variety of habitats and water flows (Haycock et al. 1997).

\section{NUTRIENT REDUCTIONS}

As expected, the most important single factor for optimal functions, when constructing wetlands for nutrient reduction, is the hydrological regime, which is basically due to precipitation, inflow, outflow, infiltration and evapotranspiration. The hydrology, by means of its variation, regulates and gives the "unique" plant composition, the primary production rate, accumulation and export of organic matter, nutrient availability and cycling, water velocity, depth and residence time (Mitsch and Gosselink 1993, Kadlec and Knight 1996). The water coverage dynamics determine the redox potential, i.e. whether the conditions in/on the substrate are anaerobic or not, a crucial factor for all plants and animals that are potential components of a functioning ecotone. Furthermore, the redox conditions are of utmost 
importance for the bacterial activities, very much ruling the effectiveness of the capacity of wetlands to reduce nitrogen, in an optimal sequence, at different depths and in various areas of a wetland, but also for transformations of carbon and sulphur. Furthermore, it is interesting to note that the presence and activities of animals and plants can very much affect the redox conditions in the sediments (Thorén 1999a).

Due to leakage of nitrate and other ions, for the farmer to get a profitable yield, nitrogen in some form has to be added to the soils. This gives a source of excessive nitrogen, which together with combustion of petroleum products result in diffuse pollution of nitrogen, mainly nitrate and ammonium $\mathrm{NH}_{4}{ }^{+}$ions, but also in organic molecules, all causing eutrophication in fresh and marine waters. Anthropogenically added water soluble nitrogen, often nitrate, is mainly due to artificial fertilisers and combustion. As this originate in atmospheric nitrogen, which is almost $80 \%$ of the air, it seems fair to revert the nitrogen to the air. Wetlands can act in this way, as the microbial activities can use (need) nitrate as electron acceptor when they degrade organic matter, and as a side product they produce the atmospheric nitrogen $\left(\mathrm{N}_{2}\right)$ ! However, as the nitrogen cycle is complicated and several requirements have to be optimised, the outcome is not easy to predict and control.

Urea $\left(\mathrm{NH}_{2}\right)_{2} \mathrm{CO}$ is a nitrogen-rich compound, which is sometimes used as de-icing agent on airport runways, but does seldom naturally occur in higher concentrations. Bacterial hydrolysis transforms urea to ammonium and nitrate, processes that are poorly understood in wetlands, with respect to importance, rates, and regulating factors, but with an urgent need to study scientifically (Thorén 1999b).

Basically, three processes can reduce nitrogen in wetlands, viz. sedimentation, biomass uptake and denitrification (Fig. 1). However, the first two are only temporary sinks, as most sediment and biomass are eventually decomposed (or redistributed), and then nitrogen reappears as nitrate, maybe via ammonium. This therefore means that sediment or plant biomass has to be removed to achieve a permanent nitrogen reduction in the ecosystem.

Denitrification is in fact a series of bacteria-mediated processes, that transforms nitrate, via nitrite and nitrous oxide, to atmospheric nitrogen, unavailable for most plants, and harmless to the water habitats. As implied, denitrification is the main and most efficient process for permanent nitrogen reduction in most wetland situations. To reach the desirable end-point of atmospheric nitrogen, increasingly anaerobic conditions must prevail. In total, the following factors and circumstances are important in order to optimise the processes (Thorén 1999a):

- A carbon source, in the form of easily degradable organic matter.

- Nitrogen in the form of nitrate (aeration can convert ammonium into nitrate).

- Temporal and/or spatial variation between aerobic and anaerobic conditions.

- A pH range of 6-8.

- Water residence time (3-5 days is recommended).

- A temperature preferentially somewhat above zero.

Also phosphorus is essential for all living organisms, and does easily result in increased primary production, eventually giving oxygen deficits and ecosystem disturbances. As no gaseous phosphorus exist, only incorporation into organism biomass and sediment can reduce water concentrations, incl. adsorption to metals, and clay and humic particles. Thus, at assimilation or decomposition phosphorus will eventually be activated again, and will remain within the aquatic system. However, harvesting the plants and using them elsewhere (e.g. as green fertiliser) would counteract this. 


\section{TREATING STORM WATER}

Storm water is a somewhat vague term for most water flowing in urban areas, often from nonpermeable surfaces, giving various mixtures of anthropogenic pollutants. Therefore the content of storm waters can vary, but are here described from "the road perspective", as several wetland arrangements have been made in such connections (Thorén 1998). Water runoff from roads contain a lot of different pollutants like suspended particles, oxygendemanding organic matter, nutrients, various hydrocarbons, heavy metals and microorganisms. The amounts of such compounds in the storm water vary substantially, often related to the weather situation, but only suspended particles, heavy metals and organic compounds are directly related to the traffic intensity. The toxicity and movements of these pollutants that reach the soil depend mainly on their solubility and mobility. Having reached the soil/sediment in the artificial wetlands, ponds and infiltration areas, these can act as "prerecipient waters", where the fate of the specific pollutants is affected by several circumstances. Important examples are conditions as $\mathrm{pH}$, redox status, water level, soil structure, organic content, various inorganic compounds, and processes as dilution, sedimentation, adsorption, chemical transformation/degradation and uptake and bioturbation by organisms (Fig. 1).

The philosophy behind the use of wetlands for inhibiting the potential effects of storm water can certainly be discussed. After some time, depending on the factors above, the wetland might approach its "saturation" of the toxicants. Then comes the choice: Is it self-evidently wise to concentrate the harmful substances, so that we hopefully "know where they are" (but still at a risk)? Should we then transport them, with the total organism set-up, elsewhere, where toxicants can not be emitted? A problem might also be that we have no ideas how dangerous it is for the water ecosystems to "move the wetland" when the saturation of toxicants has become very high.

\section{BIODIVERSITY}

Today politicians, administrators, journalists and other "powerful trend-setters" want to show environmental responsibility by advocating for an increased biodiversity ( = variation of biological organisms, often equivalent to number of species). Certainly, this is positive and promising for the progress towards a more sustainable and environmentally sound society. Without going too deep into the subject, it can be concluded that the biodiversity interest is of value not only for amateur naturalists, conservationists and scientists in ecology. Moreover, a fundamental statement is the awareness that the biodiversity also seems to be of importance for the functions of ecosystems (Herrmann 1999). Many of these functions give us important "ecological services", crucial for our society, and which we really need to care for, to be able to use them in a sustainable manner.

Thus, increased biodiversity is suggested to give several advantages for the functioning of the wetlands (Fig. 1):

A more complete and diverse shredding invertebrate community (those insects and crustaceans that fragment the organic matter), will be more efficient. This would facilitate the next step of decomposition, i.e. the bacteria, thus the most important actors in the denitrification process.

A complex plant community can be expected to give various surfaces and conditions, promoting a more effective biofilm on the plants, involved in the denitrification. 
- The plant biomass gives the needed carbon source for the denitrification, and with a complex composition might follow better conditions for this process.

A diverse community of fish, invertebrates, and birds increases the bioturbation rate, i.e. the "digging" in the bottom, which will increase the surface renewal and cycling of nutrients, but will also enhance the development of complex and changing aerobic/anaerobic bottoms, thus enhancing the denitrification process.

- When treating storm water in wetlands, a more luxuriant vegetation will be able to accumulate more of metals and other pollutants, which can also be a problem (see above).

Particularly, it should be emphasised that all kinds of wetlands are examples of the concept "ecotone", with its advantages (see above). Ecotones result not only in larger varieties of different habitats and organisms, more efficient processes, and perhaps enhanced stability, but also supply us with beloved areas for recreation and esthetical experiences.

\section{CONCLUDING REMARKS}

Probably hundreds of wetlands, dams and bufferzones have been constructed in Sweden during the last decade. However, the effects, with respect to reduction of mainly nutrients, especially nitrogen, are seldom evaluated at all, or not in a correct way. Leonardson (1994) gives an average value of $500 \mathrm{~kg} \mathrm{~N} / \mathrm{ha}$ and year, a level however not seldom exceeded, as for the up to ten times higher figures, compiled by Thorén (1999a). The variation is very large, and too often the figures have a tinge of "snap-shot". Further, at conditions giving high absolute reductions, the relative (by percentage) effects can be rather small, and vice versa (Fleischer et al. 1994, Thorén 1999a). Neither, wetland biology changes are normally evaluated, in spite of often suggested positive effects on biodiversity, and the supposed relation to important ecosystem functions.

Today, we all, but perhaps especially municipalities and other authorities, have the responsibility to promote activities in order to implement and apply the messages of Agenda 21 from the Rio Conference, one important issue being to involve all citizens in the new thinking towards a better environmental awareness and acting. Then we should realise that wetlands, and all kinds of fresh water bodies, are in fact very useful and appropriate as a pedagogical tool and potential in this ambition and responsibility. This is very clear also when applied to a whole catchment area concept, from which we can get interesting connections to all the ways that our society influences the environmental conditions, and including also economy, history and psychology. This is also congruent with the recent demands from the EU to administrate our surface waters in watershed units, as opposed to our old legislative patterns.

Nevertheless, the wetlands remain, and are as important as in earlier times, so they have to be developed, restored, and more numerous, for the purpose of increased water quality and biodiversity, good for "body and soul" of us all.

\section{ACKNOWLEDGEMENTS}

Thanks are due to Anders Boström for constructive work with the draft, and constructing the figure. 


\section{REFERENCES}

Finlayson Mand Moser M (1991). Wetlands, facts on file. - Oxford, 224 pp.

Fleischer S, Gustafsson A, Joelsson A, Pansar J and Stibe L (1994). Nitrogen Removals in Created Ponds. - Ambio 23: 349-357.

Gee JHR, Smith BD, Lee KM and Griffiths SW (1997). The ecological basis of freshwater pond management for biodiversity. - Aquatic Conserv: Mar. Freshw. Ecosyst. 7: 91-104. DOI: https://doi.org/10.1002/ (SICI)1099-0755 (199706)7:2<91::AID-AQC221>3.0.CO;2-O

Haycock NE, Burt TP, Goulding KWT och Pinay G (1997). Buffer zones; their processes and potential in water protection. - Quest Environmental; Harpenden, UK. 322 sid.

Herrmann J (1999). Freshwater biodiversity and ecosystem functions; the ideas and the case River Emån. - In: Friberg N \& Carl JD (eds). Biodiversity in Benthic Ecology. Proc. Nordic Benth. Meeting, Silkeborg, Denmark, 13-14 November 1997. NERI Tech. Report No. 266, p. 77-82.

Kadlec RH and Knight RI (1996). Treatment wetlands. - CRC Press Inc.

Lachavanne J-B and Juge R (1997). Biodiversity in Land-Inland Water Ecotones. - Man and the Biosphere, Vol 18.

Leonardson L (1994). Våtmarker som kvävefällor, Svenska och internationella erfarenheter (Wetlands as nitrogen sinks, Swedish and international experience). - EPA Report 4176. (English summary)

Mitsch WJ and Gosselink JG (1993). Wetlands. - Van Nostrand Reinhold Publ. 722 pp.

Swedish EPA (1997). Kväveefrån land till hav (Nitrogen from land to sea). - EPA Report 4735, 112 pp. (No English summary)

Thorén A-K (1998). Vägdagvattendammar för yt- och grundvattenskydd (Road storm water dams for protection of surface and ground water). - University of Kalmar, Report 1998:8, 18 pp. (No English summary)

Thorén A-K (1999a). Våtmarker som närsaltreducerande åtgärder $i$ Gamlebyvikens tillrinningsområde (Wetlands as nutrient reducing measures in the Gamlebyviken catchment areai). - University of Kalmar, Examination project 10 points, $59 \mathrm{pp}$. (English summary)

Thorén A-K (1999b). Ureaomsättning och dess betydelse för kvävereduktion $i$ våtmarker; fallet Kalmar Dämme (Urea transformation and nitrogen reduction in wetlands; the case Kalmar Dämme). - University of Kalmar, report 1999:4, 50 pp. (English summary) 